\title{
Circulating bioactive adrenomedullin as a marker of sepsis, septic shock and critical illness
}

Oscar H. M. Lundberg ${ }^{1,2^{*}} \mathbb{D}$, Maria Lengquist ${ }^{1,2}$, Martin Spångforss ${ }^{1,3}$, Martin Annborn ${ }^{1,4}$, Deborah Bergmann ${ }^{5}$, Janin Schulte ${ }^{5}$, Helena Levin ${ }^{1}$, Olle Melander ${ }^{6,7}$, Attila Frigyesi ${ }^{1,2}$ and Hans Friberg ${ }^{1,2}$

\begin{abstract}
Background: Biomarkers can be of help to understand critical illness and to identify and stratify sepsis. Adrenomedullin is a vasoactive hormone, with reported prognostic and potentially therapeutic value in sepsis. The primary aim of this study was to investigate the association of circulating bioactive adrenomedullin (bio-ADM) levels at intensive care unit (ICU) admission with mortality in sepsis patients and in a general ICU population. Secondary aims included the association of bio-ADM with organ failure and the ability of bio-ADM to identify sepsis.

Methods: In this retrospective observational study, adult patients admitted to one of four ICUs during 2016 had admission bio-ADM levels analysed. Age-adjusted odds ratios (OR) with 95\% Cl for log-2 transformed bio-ADM, and Youden's index derived cut-offs were calculated. The primary outcome was 30-day mortality, and secondary outcomes included the need for organ support and the ability to identify sepsis.
\end{abstract}

Results: Bio-ADM in 1867 consecutive patients were analysed; 632 patients fulfilled the sepsis-3 criteria of whom 267 had septic shock. The median bio-ADM in the entire ICU population was $40 \mathrm{pg} / \mathrm{mL}, 74 \mathrm{pg} / \mathrm{mL}$ in sepsis patients, 107 $\mathrm{pg} / \mathrm{mL}$ in septic shock and $29 \mathrm{pg} / \mathrm{mL}$ in non-septic patients. The association of elevated bio-ADM and mortality in sepsis patients and the ICU population resulted in ORs of 1.23 (95\% Cl 1.07-1.41) and 1.22 (95\% Cl 1.12-1.32), respectively. The association with mortality remained after additional adjustment for lactate in sepsis patients. Elevated bioADM was associated with an increased need for dialysis with ORs of $2.28(95 \% \mathrm{Cl} 2.01-2.59)$ and $1.97(95 \% \mathrm{Cl} 1.64-$ 2.36) for the ICU population and sepsis patients, respectively, and with increased need of vasopressors, OR 1.33 (95\% Cl 1.23-1.42) (95\% Cl 1.17-1.50) for both populations. Sepsis was identified with an OR of 1.78 (95\% Cl 1.64-1.94) for bio-ADM, after additional adjustment for severity of disease. A bio-ADM cut-off of $70 \mathrm{pg} / \mathrm{mL}$ differentiated between survivors and non-survivors in sepsis, but a Youden's index derived threshold of $108 \mathrm{pg} / \mathrm{mL}$ performed better.

Conclusions: Admission bio-ADM is associated with 30-day mortality and organ failure in sepsis patients as well as in a general ICU population. Bio-ADM may be a morbidity-independent sepsis biomarker.

Keywords: Critical illness, Sepsis, Septic shock, Adrenomedullin, Bioactive adrenomedullin, Biomarkers, Cut-off

*Correspondence: oscar.lundberg@med.lu.se

2 Department of Intensive and Perioperative Care, Skåne University Hospital, 20502 Malmö, Sweden

Full list of author information is available at the end of the article

\section{Introduction Background}

Sepsis is a condition with high mortality and suffering, affecting millions of people yearly across all ages and backgrounds [1]. original author(s) and the source, provide a link to the Creative Commons licence, and indicate if changes were made. The images or other third party material in this article are included in the article's Creative Commons licence, unless indicated otherwise in a credit line to the material. If material is not included in the article's Creative Commons licence and your intended use is not permitted by statutory regulation or exceeds the permitted use, you will need to obtain permission directly from the copyright holder. To view a copy of this licence, visit http://creativecommons.org/licenses/by/4.0/. The Creative Commons Public Domain Dedication waiver (http://creativeco mmons.org/publicdomain/zero/1.0/) applies to the data made available in this article, unless otherwise stated in a credit line to the data. 
Since sepsis is a syndrome encompassing a variety of illnesses with multiple pathophysiologies, there is no broadly applicable single efficient treatment pathway.

New methods for stratification and classification of sepsis are warranted in order to better tailor the care of septic patients. The use of biomarkers can potentially help us understand and categorise sepsis into phenotypes [2] and thereby add value to existing risk and severity scoring systems as well as guiding treatment. Further, a better understanding of hormonal systems, which some biomarkers are derived from, can open up for new therapeutical pathways.

\section{Adrenomedullin}

Adrenomedullin (ADM) is a 52-amino acid peptide hormone first discovered in human pheochromocytoma cells [3], but is produced by many different cell types [4]. ADM plays a part in the homeostasis of cardiovascular, endocrine, renal and immunological systems and has a role in the electrolyte balance [3-6]. More specifically, ADM has vasodilatory properties $[7,8]$ by binding to receptors on both endothelial and smooth muscle cells [9]. Further, ADM is capable of modulating the endothelial barrier, where it has a stabilising effect [9].

\section{Adrenomedullin in sepsis}

Over the last fifteen years, the role of ADM in sepsis has been investigated. Several studies have reported an association of increased levels of ADM and poor outcomes among patients with sepsis and septic shock [10-16]. The role of ADM in patients with a cardiopulmonary disease has also drawn attention [17-24]. These studies have used two assays measuring different fragments from the ADM precursor, mid regional pro adrenomedullin (MRproADM) [25] and circulating bioactive adrenomedullin (bio-ADM) [12], making results difficult to compare. A cut-off value of $70 \mathrm{pg} / \mathrm{mL}$ bio-ADM has been used, which originates from Marino and colleagues [12]. It is not clear how this threshold was chosen, but the authors reported a $100 \% 28$-day survival rate in a minimal subgroup $(n=$ 12) where a reduction of bio-ADM levels to below $70 \mathrm{pg} /$ $\mathrm{mL}$ was observed.

In animal models of sepsis, however, exogenous ADM has led to improved outcomes[26-28], why ADM has been referred to as a double-edged sword [29]. Further, modulation of the ADM hormonal system using antibodies against a non-ligand binding site of ADM has been suggested a potential therapy in sepsis [30]. This is currently investigated in a phase II clinical trial [31], where septic patients with initial levels of bio-ADM $>70 \mathrm{pg} /$ $\mathrm{mL}$ are randomised to receive either the human ADM antibody adrecizumab or placebo [31]. Since ADM levels in non-septic and non-cardiopulmonary critical care patients are poorly investigated, we decided to perform this exploratory study.

\section{Objectives}

The primary aim of this study was to investigate the association of admission bio-ADM with mortality in patients fulfilling the sepsis criteria and in a large mixed general ICU population. Secondary aims were to investigate the association of bio-ADM with organ failure in the ICU, measured as need of circulatory and renal support, and the ability to identify sepsis. Further, we aimed to perform a validation of the proposed cut-off value of $70 \mathrm{pg} /$ $\mathrm{mL}$.

\section{Methods}

\section{Study design and setting}

The present study was a retrospective multicentre observational study of patients consecutively admitted to one of four general (mixed surgical and medical) ICUs in the Skåne Region (Scania county), Sweden, in 2016. The Strengthening the Reporting of Observational Studies in Epidemiology (STROBE) guidelines were followed [32].

\section{Participants}

All adult ICU admissions with valid admission blood samples were included. When direct transfers occurred between the participating ICUs, follow-up data were merged to form cohesive ICU admissions. Transfers from other ICUs were excluded since our aim was to limit our study to primary admissions to intensive care. Information was given to the patient or next of kin, and information letters were sent home to surviving patients 2-6 months after hospital discharge. Patient consent was on an opt-out basis. For deceased patients, consent was presumed.

\section{Variables}

The primary outcome was 30-day mortality in sepsis patients and the general ICU population. Secondary outcomes were: (1) need of cardiovascular support, defined as cardiovascular sequential organ failure assessment (SOFA) score $\geq 3$, at ICU admission, (2) need for continuous renal replacement therapy (CRRT) during ICU-stay and (3) identification of sepsis at ICU admission.

\section{Sepsis cohort}

The process of identifying the sepsis population, and collection of background data for this cohort, has previously been described in detail [33].

In brief, the sepsis-3 criteria [34] were used to identify patients with sepsis, defined as a SOFA score $\geq 2$ on ICU admission with a suspicion of infection within $24 \mathrm{~h}$ before or $24 \mathrm{~h}$ after ICU admission. A suspected infection 
was defined by blood culture sampling and concomitant administration of oral or intravenous antibiotics $(24 \mathrm{~h}$ before to $72 \mathrm{~h}$ after blood culture), as suggested by the sepsis-3 task force [34].

The predefined exclusion criteria for sepsis admissions were: (1) elective ICU admission after elective surgery, and (2) cardiac arrest within $6 \mathrm{~h}$ before or $1 \mathrm{~h}$ after ICU admission.

Septic shock was defined as the need of a vasopressor, identified by either a cardiovascular SOFA score $\geq 3$ or after a medical record review, and a lactate level of $\geq 2$ $\mathrm{mmol} / \mathrm{L}$ among those fulfilling sepsis criteria on ICU admission.

\section{Data sources}

Background and survival data were extracted from the patient administrative system for Intensive care units (PASIVA). PASIVA is the portal by which the treating physician and nursing staff submit prospectively collected laboratory and physiological data to the Swedish Intensive Care Registry. PASIVA is synchronised with the Swedish population register, which contains survival data.

Medical records were reviewed retrospectively by trained data collectors to identify sepsis criteria and additional background data [33].

\section{Bio-ADM measurement}

Blood samples, used for the analysis of bio-ADM, were collected on ICU admission and then centrifuged, aliquoted, frozen, and stored in the SWECRIT biobank at Region Scania (BD-47, SC-1922). Samples collected later than $6 \mathrm{~h}$ after ICU admission were excluded. If the sampling time was missing, samples were included if the time of freezing was within $6 \mathrm{~h}$. Frozen plasma samples were shipped, and batch analysis of bio-ADM was performed on thawed samples in March 2019 at the laboratory of SphingoTec GmbH (Hennigsdorf, Germany). The assay has previously been described elsewhere [35].

\section{Study size}

The study size was not predetermined but rather a convenience sample. All adult ICU admissions from 2016, with valid admission blood samples and consent, in the SWECRIT biobank constituted our study material.

\section{Statistics}

For all hypothesis tests, we considered $p$ values $<0.05$ as significant. To assess a difference in the location of two independent variables, we used the Wilcoxon rank-sum test (Mann-Whitney U test). Differences in proportions were assessed using Pearson's $\chi^{2}$ test. Medians were reported with their corresponding interquartile ranges
(IQR). The Swedish 2016 calibration of the Simplified Acute Physiology Score III (SAPS3) was used to calculate the estimated 30-day mortality risk $\left(\mathrm{EMR}_{30 \text {-day }}\right)[36$, 37]. Multivariable binary logistic regression, adjusted for age, was used to analyse outcomes. The results of the regression analyses are reported as odds ratios (OR) with 95\% confidence intervals (CI). The regression models were evaluated with the Hosmer-Lemeshow goodnessof-fit test with ten groups, and models resulting in significant tests were marked [38]. To adjust for severity of disease, SAPS3 was included in the regressions. If a parameter, due to skewness, needed transformation, the base 2 logarithm was used. The difference in KaplanMeier curves was evaluated with the log-rank test [39]. Areas under the curve (AUC) were derived from receiver operating characteristic (ROC) curves[40]. Differences in AUCs were tested with the method of DeLong et al. [41]. Youden's index derived thresholds were reported [42]. Admissions with missing data for any variable were excluded for mean and median calculations. If a variable had missing values, the number of observations available was specified.

\section{Results}

\section{Participants}

There were 2724 adult admissions in 2016. After merging and exclusion, 1867 admissions with valid samples remained, constituting our study population, shown in Fig. 1 . The ICU study population was then divided into a sepsis and a non-sepsis cohort, with 632 and 1235 admissions, respectively.

\section{Demographics}

Patients in the sepsis cohort were generally older and sicker on admission with higher illness severity scores than patients in the non-sepsis cohort, as seen in Table 1. Septic patients were, to a greater extent, admitted from within the hospital, while non-septic patients more often were admitted from the emergency department and directly after surgery. The suspected focus of infection for the sepsis patients is shown in Additional file 1: Table S1. Positive blood cultures with the most common pathogens are displayed in Additional file 1: Fig. S1.

\section{Outcomes}

Mortality rates for the ICU population, sepsis cohort and non-sepsis cohort are shown in Table 1 . The sepsis cohort had worse survival data, a greater need for organ support with significantly higher cardiovascular SOFA scores and a higher proportion of CRRT, and a longer ICU stay. A more detailed description of sepsis patients, divided into 30-day survivors and non-survivors, is shown in Table 2. Sepsis patients who did not survive were older and sicker, 


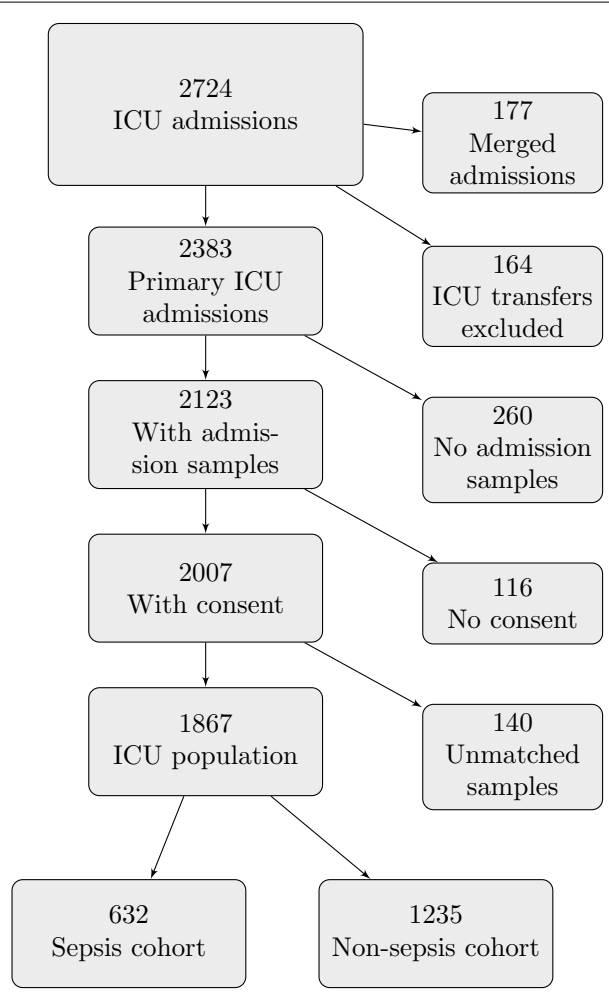

Fig. 1 Flow chart of ICU admissions, admission samples and consent. ICU: Intensive care unit

but with similar pre-existing comorbidities and a similar degree of septic shock on ICU admission, as survivors. Forty-two per cent of sepsis patients fulfilled the septic shock criteria on admission. This subgroup had a 30-day mortality rate of $30.1 \%$, compared to $25.2 \%$ in nonshock patients $(p=0.15)$. $\mathrm{EMR}_{30 \text {-day }}$ among septic shock patients was $40.3 \%$ (22.5-58.9), while non-shock patients had an $\mathrm{EMR}_{30 \text {-day }}$ of $24.2 \%$ (12.2-44.5).

\section{Bio-ADM}

The range of bio-ADM was $8-4689 \mathrm{pg} / \mathrm{mL}$, and since the distribution was highly skewed, a logarithmic transformation was used, see Fig. 2. The median time from admission to sampling was $25 \mathrm{~min}(15-40)$.

\section{Bio-ADM and mortality}

Dividing patients by quartiles of bio-ADM resulted in significant survival separation in the sepsis cohort as well as in the entire ICU population, as seen in Fig. 3.

Within the sepsis cohort, non-survivors had significantly higher levels of bio-ADM compared to survivors, shown in Table 2.

The associations of bio-ADM in the regression models for 30-day mortality were almost identical in the sepsis cohort and in the entire ICU population, as in Table 3. A doubling of bio-ADM generated a $22-23 \%$ increased OR for death.

In the model where admission lactate among septic patients was added as a covariate, bio-ADM was still significantly associated with 30-day mortality with an OR of 1.20 (1.04-1.38). The OR for lactate in the same model was 1.24 (1.06-1.45), $p=0.009$. When SAPS3 and bioADM were applied in the same model for mortality, the association of bio-ADM and mortality was non-significant (data not shown).

The predictive accuracy for bio-ADM and 30-day mortality in the sepsis cohort, presented as AUC, in addition to c-reactive protein (CRP) and lactate are shown in Additional file 1: Table S2.

\section{Bio-ADM and organ support}

The association of bio-ADM with CRRT was strong in the sepsis cohort with OR 1.97 (1.64-2.36) but even stronger in the general ICU population, OR 2.28 (2.01-2.59). The ORs for a cardiovascular SOFA score 3 or 4 were 1.33 for both the septic (1.17-1.50) and the general ICU patients (1.23-1.42), as in Table 3.

\section{Bio-ADM in sepsis and as a sepsis marker}

The median bio-ADM in the sepsis cohort was more than twice as high as the median in the non-sepsis group, as in Table 1 . The median bio-ADM in the septic shock subgroup was $107 \mathrm{pg} / \mathrm{mL}$ (58-188) compared to $62 \mathrm{pg} / \mathrm{mL}$ (35-116) in sepsis patients not presenting with shock $(p<0.001)$. In Table 3 , the association of increased bioADM levels and the risk of having sepsis and septic shock is presented. The OR of having sepsis in the entire ICU population was 1.78 (1.64-1.94) after adjustment for severity of disease.

In the ICU population, the AUC $(95 \% \mathrm{CI})$ of bio-ADM to identify sepsis was $0.76(0.73-0.78)$, see Additional file 1: Table S2. A Youden's index derived threshold of 37 $\mathrm{pg} / \mathrm{mL}$ for detecting sepsis resulted in a sensitivity and specificity of $61 \%$ and $80 \%$, respectively.

\section{Bio-ADM cut-offs}

The cut-off of $70 \mathrm{pg} / \mathrm{mL}$ separated the ICU population into high and low bio-ADM, as shown in Table 1. The same information is shown graphically in Fig. 2. The sensitivity for 30-day mortality using a cut-off of $70 \mathrm{pg} /$ $\mathrm{mL}$ was $42 \%$ with a corresponding specificity of $73 \%$ in the ICU population. For the sepsis cohort, the sensitivity and specificity were $60 \%$ and $50 \%$ for 30 -day mortality, respectively. Kaplan-Meier curves and results from log-rank tests for bio-ADM levels above or below 70 $\mathrm{pg} / \mathrm{mL}$ are displayed in Fig. 4. Youden's index identified a threshold for survival prediction of $45 \mathrm{pg} / \mathrm{mL}$ in the ICU population and $108 \mathrm{pg} / \mathrm{mL}$ in the sepsis cohort. A 
Table 1 Demographics and outcomes of the ICU population and a comparison between the sepsis and non-sepsis cohorts

\begin{tabular}{|c|c|c|c|c|}
\hline & ICU population & Sepsis cohort & Non-sepsis cohort & $p$ value \\
\hline Number, $n$ (\% of ICU population) & $1867(100)$ & $632(33.9)$ & $1235(66.1)$ & \\
\hline Age in years, median (IQR) & $67(54-75)$ & $69(61-76)$ & $65(49.5-73)$ & $<0.001$ \\
\hline Female sex, $n(\%)$ & $738(39.5)$ & $251(39.7)$ & $487(39.4)$ & 0.95 \\
\hline \multicolumn{5}{|l|}{ Department of origin } \\
\hline Emergency department/out of hospital, $n$ (\%) & $896(48)$ & $276(43.7)$ & $620(50.2)$ & 0.008 \\
\hline Hospital ward, $n$ (\%) & $604(32.4)$ & $282(44.6)$ & $322(26.1)$ & $<0.001$ \\
\hline Intermediate, $n(\%)$ & $50(2.7)$ & $32(5.1)$ & $18(1.5)$ & $<0.001$ \\
\hline Operating room/postoperative ward, $n(\%)$ & $317(17)$ & $42(6.6)$ & $275(22.3)$ & $<0.001$ \\
\hline \multicolumn{5}{|l|}{ Organ dysfunction and illness severity on ICU admission } \\
\hline SAPS3 score, median (IQR) & $59(47-71)$ & $66(57-77)$ & $54(43-67)$ & $<0.001$ \\
\hline SAPS3 EMR E-day' median (IQR) & $17.6(5.2-40.3)$ & $29.9(14.8-53)$ & $11.1(3.1-31.9)$ & $<0.001$ \\
\hline SOFA score, median (IQR) & $6(3-9)$ & $7(5-10)$ & $4(1-8)$ & $<0.001$ \\
\hline Cardiovascular SOFA score $(n=1836)$, median (IQR) & $1(0-3)$ & $3(0-4)$ & $1(0-3)$ & $<0.001$ \\
\hline \multicolumn{5}{|l|}{ Outcomes } \\
\hline ICU mortality, n (\%) & $208(11.1)$ & $86(13.6)$ & $122(9.9)$ & 0.019 \\
\hline 30-day mortality, $n(\%)$ & $402(21.5)$ & $174(27.5)$ & $228(18.5)$ & $<0.001$ \\
\hline 1-year mortality, n (\%) & $622(33.3)$ & $261(41.3)$ & $361(29.2)$ & $<0.001$ \\
\hline ICU length of stay in days, median (IQR) & $1.6(0.8-3.6)$ & $2.5(1.1-5.5)$ & $1.1(0.7-2.7)$ & $<0.001$ \\
\hline CRRT use during ICU stay, $n$ (\%) & $169(9)$ & $96(15.2)$ & $73(5.9)$ & $<0.001$ \\
\hline \multicolumn{5}{|l|}{ bio-ADM } \\
\hline bio-ADM pg/mL, median (IQR) & $40(21-86)$ & $74(42-145)$ & $29(18-56)$ & $<0.001$ \\
\hline bio-ADM> 70 pg/mL, n (\%) & $564(30.2)$ & $333(52.7)$ & $231(18.7)$ & $<0.001$ \\
\hline
\end{tabular}

Data regarding general characteristics, outcomes, organ dysfunction and illness severity are presented. The sepsis cohort was compared to the non-sepsis cohort, and the $p$ values refer to that comparison. Proportions (\%) are within their subgroups unless otherwise specified. ICU: intensive care unit; IQR: interquartile range; SAPS3: Simplified Acute Physiology Score III; EMR 30 -day: estimated 30-day mortality risk; SOFA: Sequential Organ Failure Assessment; CRRT: continuous renal replacement therapy; bio-ADM: circulating bioactive adrenomedullin

separate Kaplan-Meier curve for the sepsis cohort using the Youden's index-derived cut-off of $108 \mathrm{pg} / \mathrm{mL}$ is shown in Fig. 4. Sensitivity, specificity, positive predictive values, negative predictive values, positive and negative likelihood ratios for all cut-offs are displayed in Additional file 1: Table S2.

\section{Discussion}

In this study, elevated admission bio-ADM levels were associated with increased 30-day mortality in sepsis and in the general ICU population alike. Increased bio-ADM was also associated with cardiovascular failure and need for dialysis. Furthermore, after adjustment of severity of disease, bio-ADM was strongly associated with sepsis.

\section{Bio-ADM in sepsis}

Our sepsis cohort was identified using a structured method where ICU admissions were manually screened for sepsis-3 and septic shock criteria within a narrow time window at ICU admission. Hence, the sepsis diagnosis was not based on discharge diagnose coding, which has been shown to be misleading [33, 43, 44]. We applied predefined exclusion criteria in order to ensure that our sepsis cohort would represent clinically relevant sepsis patients requiring intensive care.

Interestingly, bio-ADM on admission was associated with mortality in sepsis patients and in the general ICU population in a similar fashion. When included in the same regression model for 30-day mortality, lactate and bio-ADM both contributed independently of each other, indicating that bio-ADM carries additional information in sepsis. In line with this, Blet and colleagues, reported added prognostic value of bio-ADM in addition to lactate among septic patients [45].

Bio-ADM has repeatedly been shown to be associated with increased morbidity $[15,16]$, which also was evident in our study. Sepsis patients were generally sicker and had significantly higher bio-ADM than the general ICU population. Further, patients with septic shock had significantly higher levels of bio-ADM, which is in agreement with previous reports $[15,16,46]$.

The association of bio-ADM with sepsis remained after adjusting for severity of disease, implying that 
Table 2 Demographics and outcomes of the sepsis cohort and comparisons between 30-day non-survivors and survivors

\begin{tabular}{|c|c|c|c|c|}
\hline & Sepsis cohort & Non-survivors & Survivors & $p$ value \\
\hline Number, $n$ (\% of Sepsis cohort) & $632(100)$ & $174(27.5)$ & $458(72.5)$ & \\
\hline Age in years, median (IQR) & $69(61-76)$ & $73(66-79)$ & $68(59-75)$ & $<0.001$ \\
\hline Female sex, $n(\%)$ & $251(39.7)$ & $61(35.1)$ & $190(41.5)$ & 0.17 \\
\hline Body mass index $(n=588)$, median (IQR) & $26.6(22.9-30.7)$ & $26.7(23.3-31.2)$ & $26.3(21.8-30.5)$ & 0.11 \\
\hline \multicolumn{5}{|l|}{ Comorbidities } \\
\hline None of those listed below, $n$ (\%) & $173(27.4)$ & $46(26.4)$ & $127(27.7)$ & 0.74 \\
\hline Cardiovascular disease, $n$ (\%) & $313(49.5)$ & $87(50)$ & $226(49)$ & 0.95 \\
\hline Respiratory disease, $n(\%)$ & $156(24.7)$ & $47(27)$ & $109(23.8)$ & 0.46 \\
\hline Hepatic disease, $n(\%)$ & $32(5)$ & $12(6.9)$ & $20(4.4)$ & 0.27 \\
\hline Renal disease, $n(\%)$ & $63(10.0)$ & $18(10.3)$ & $45(9.8)$ & 0.96 \\
\hline Cancer, $n(\%)$ & $109(17.3)$ & $37(21.3)$ & $72(15.7)$ & 0.13 \\
\hline Haematological disease, $n(\%)$ & $47(7.4)$ & $17(9.8)$ & $30(6.6)$ & 0.23 \\
\hline Immunosuppression, $n$ (\%) & $126(19.9)$ & $41(23.6)$ & 85 (18.6) & 0.20 \\
\hline Diabetes, $n(\%)$ & $167(26.4)$ & $40(23.0)$ & $127(27.7)$ & 0.27 \\
\hline Modified Charlson comorbidity index, median (IQR) & $1(0-2)$ & $2(0-2)$ & $1(0-2)$ & 0.54 \\
\hline \multicolumn{5}{|l|}{ Department of origin } \\
\hline Emergency department/out of hospital, $n$ (\%) & $276(43.7)$ & $62(35.6)$ & $214(46.7)$ & 0.012 \\
\hline Hospital ward, $n(\%)$ & $282(44.6)$ & $87(50)$ & $195(42.6)$ & 0.094 \\
\hline Intermediate, $n(\%)$ & $32(5.1)$ & $13(7.5)$ & $19(4.1)$ & 0.089 \\
\hline Operating room/postoperative ward, $n(\%)$ & $42(6.6)$ & $12(6.9)$ & $30(6.6)$ & 0.88 \\
\hline \multicolumn{5}{|l|}{ Organ dysfunction and illness severity on ICU admission } \\
\hline SAPS3 score, median (IQR) & $66(57-77)$ & $76(66-82)$ & $63(56-73)$ & $<0.001$ \\
\hline SAPS3 EMR 30 -day' median (IQR) & $29.9(14.8-53)$ & $50.9(29.9-62.7)$ & $24.2(13.5-44.5)$ & $<0.001$ \\
\hline SOFA score, median (IQR) & $7(5-10)$ & $9(6-11)$ & $7(5-9)$ & $<0.001$ \\
\hline Cardiovascular SOFA score $(n=625)$, median (IQR) & $3(0-4)$ & $3(1-4)$ & $3(0-4)$ & 0.037 \\
\hline Septic shock, n (\%) & $267(42.2)$ & $82(47.1)$ & $185(40.4)$ & 0.15 \\
\hline \multicolumn{5}{|l|}{ Outcomes } \\
\hline ICU length of stay in days, median (IQR) & $2.5(1.1-5.5)$ & $2.7(1.2-6.2)$ & $2.4(1-4.9)$ & 0.16 \\
\hline CRRT use during ICU stay, n (\%) & $96(15.2)$ & $38(21.8)$ & $58(12.7)$ & 0.006 \\
\hline \multicolumn{5}{|l|}{ Biomarkers } \\
\hline bio-ADM pg/mL, median (IQR) & $74(42-145)$ & $93(51-173)$ & $70(39-131)$ & $<0.001$ \\
\hline bio-ADM > 70 pg/mL, $n(\%)$ & $333(52.7)$ & $104(59.8)$ & $229(50)$ & 0.035 \\
\hline Lactate $(n=626) \mathrm{mmol} / \mathrm{L}$, median (IQR) & $2.8(1.5-4.9)$ & $3.3(1.7-5.7)$ & $2.5(1.4-4.6)$ & 0.002 \\
\hline $\mathrm{CRP}(n=600) \mathrm{mg} / \mathrm{L}$, median $(\mathrm{IQR})$ & $113(35-241)$ & $143(47-238)$ & $102(32-242)$ & 0.13 \\
\hline
\end{tabular}

Data regarding general characteristics, outcomes, organ dysfunction and illness severity are presented. Non-survivors were compared to survivors, and the $p$ values refer to that comparison. Proportions (\%) are within their subgroups unless otherwise specified. IQR: interquartile range; SAPS3: Simplified Acute Physiology Score III; $\mathrm{EMR}_{30 \text {-day: }}$ estimated 30-day mortality risk; SOFA: Sequential Organ Failure Assessment; ICU: intensive care unit; CRRT: continuous renal replacement therapy; bio-ADM: circulating bioactive adrenomedullin

elevated levels of bio-ADM on ICU admission makes it more likely that a patient has sepsis.

To our knowledge, there have been no previous reports on the sepsis discriminating properties of bio-ADM in a general ICU population. The ability of bio-ADM to identify sepsis patients was modest with an AUC of 0.76. A Youden's index derived cut-off of $37 \mathrm{pg} / \mathrm{mL}$ generated a sensitivity of $61 \%$ and a specificity of $80 \%$, which indicates limited clinical utility of that cut-off.

\section{Bio-ADM in critical care}

The finding that bio-ADM could be broadly applicable to critically ill patients has been reported previously [46]. Lemasle and colleagues studied a large population of patients requiring vasopressor or invasive ventilation for more than $24 \mathrm{~h}$ and found an association of bio-ADM with mortality and need for organ support. Their patient population was, however, sicker in comparison with ours. In addition, the bio-ADM samples were not admission 


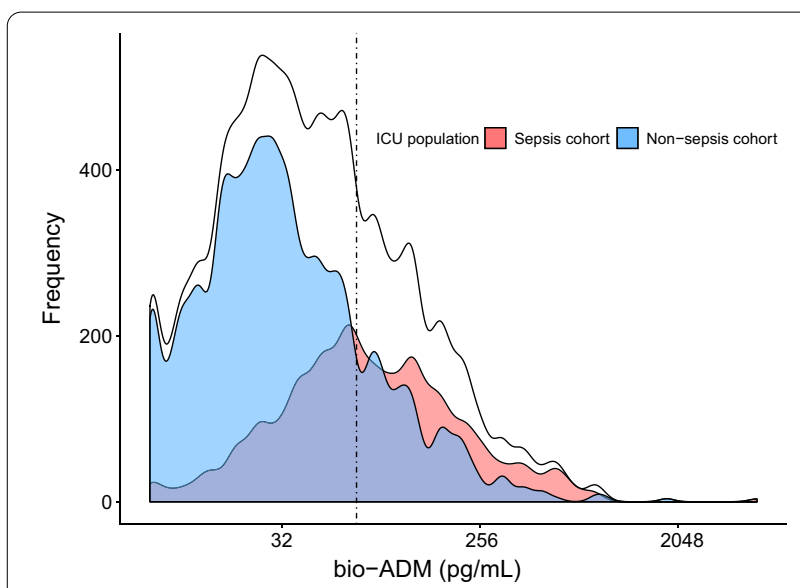

Fig. 2 Distribution of bio-ADM in the ICU population, Sepsis cohort and Non-sepsis cohort. X-axis logarithmic with base 2. The dotted line represents a concentration of $70 \mathrm{pg} / \mathrm{mL}$. ICU: intensive care unit; bio-ADM: circulating bioactive adrenomedullin

samples, which could explain the lower bio-ADM median level in our study $(40 \mathrm{pg} / \mathrm{mL}$ versus $66 \mathrm{pg} / \mathrm{mL})$.

\section{Bio-ADM cut-offs}

In spite of the questionable rationale of using a cut-off of $70 \mathrm{pg} / \mathrm{mL}$ for bio-ADM in sepsis, it has been used in several studies since it was first proposed [12].

In the present study, the $70 \mathrm{pg} / \mathrm{mL}$ cut-off managed to separate survivors from non-survivors, but a Youden's index derived cut-off of $108 \mathrm{pg} / \mathrm{mL}$ performed better in sepsis patients, see Fig. 4. Interestingly, Mebazaa et al. reported a similar Youden's index cut-off of $102 \mathrm{pg} / \mathrm{mL}$ from their sepsis cohort in a recent study [15]. For the entire ICU population, the Youden's index identified the cut-off $45 \mathrm{pg} / \mathrm{mL}$, which is a novel finding for bio-ADM.

\section{Limitations}

There are several limitations to this study.

The study was designed to focus on bio-ADM levels in sepsis patients. All ICU admissions were initially screened for sepsis-3 criteria, and the aim of our data retrieval was primarily to collect detailed data from this cohort. For the remaining ICU population, collection of data was by necessity limited to the PASIVA database, which resulted in different data availability for the sepsis and non-sepsis cohorts. We did, for example, not collect data on comorbidities systematically nor lactate or c-reactive protein levels in the non-sepsis cohort.

We did not have information on the volume status of the patients, nor whether adequate volume resuscitation measures were taken before vasopressor treatment was commenced, a diagnostic criterion for septic shock. However, this limitation is a common feature of studies aiming at identifying septic shock. Initiation of vasopressor therapy in the ICU would usually imply that adequate fluid resuscitation was done, assuming adherence to the Surviving Sepsis Guidelines [47].

We used a strict time frame in which we identified the sepsis and non-sepsis patients and did not investigate the development of sepsis or septic shock beyond
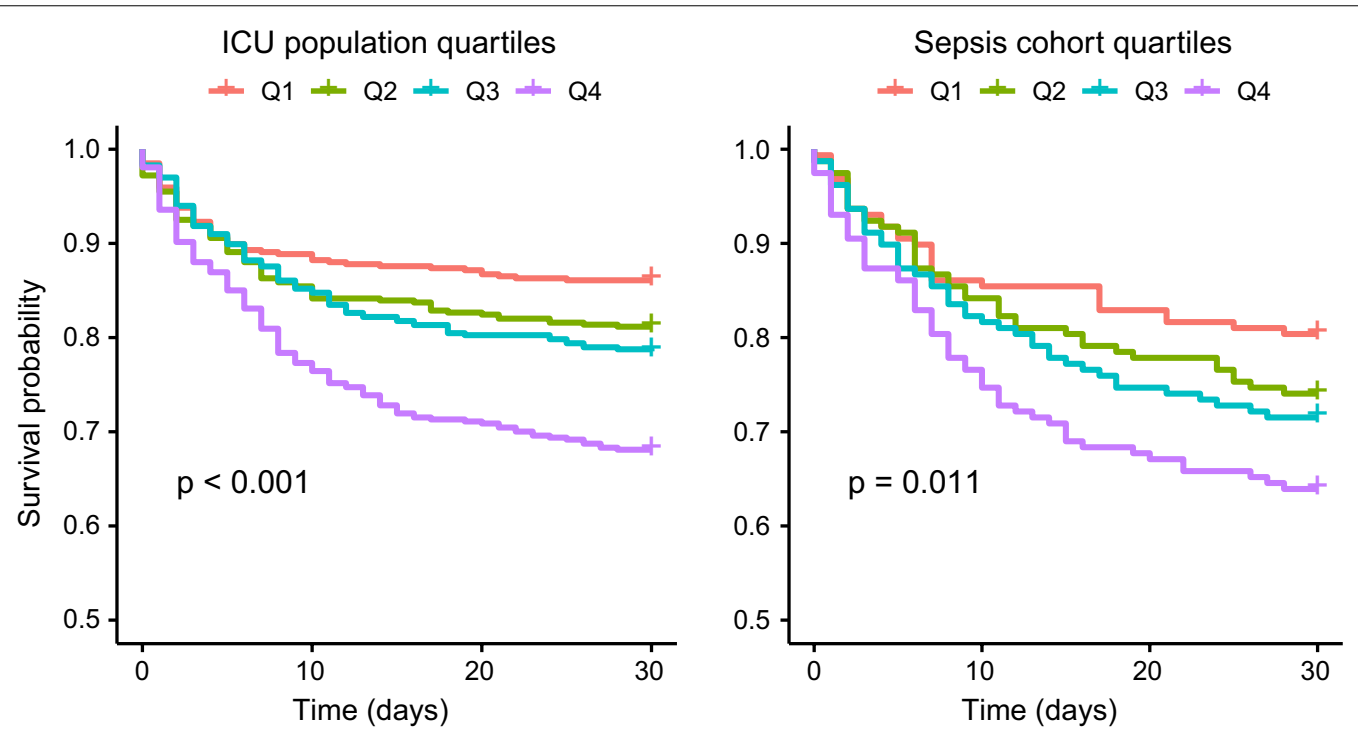

Fig. 3 Kaplan-Meier curves for the ICU population and the sepsis cohort according to quartiles of bio-ADM. The range of bio-ADM (pg/mL) in the quartiles in the ICU populations was $\langle 21 ; 21-40 ; 40-86 ;>86$ and in the sepsis cohort $\langle 42 ; 42-74 ; 74-145 ;>145$. The $p$ values were derived from the log-rank test. ICU: intensive care unit; bio-ADM: circulating bioactive adrenomedullin; Q1: quartile 1; Q2: quartile 2; Q3: quartile 3 Q4: quartile 4 
Table 3 Odds ratios for bio-ADM from multivariable binary logistic regression analyses for different outcomes

\begin{tabular}{|c|c|c|c|c|c|c|}
\hline \multirow[t]{2}{*}{ Outcome } & \multicolumn{3}{|c|}{ ICU population } & \multicolumn{3}{|c|}{ Sepsis cohort } \\
\hline & OR & $95 \% \mathrm{Cl}$ & $p$ value & OR & $95 \% \mathrm{Cl}$ & $p$ value \\
\hline 30-day mortality & 1.22 & $1.12-1.32$ & $<0.001$ & 1.23 & $1.07-1.41$ & 0.003 \\
\hline 30-day mortality ${ }^{\dagger}$ & N/A & N/A & N/A & 1.20 & $1.04-1.38$ & 0.010 \\
\hline Cardiovascular SOFA $\geq 3$ & 1.33 & $1.23-1.42$ & $<0.001$ & 1.33 & $1.17-1.50$ & $<0.001$ \\
\hline CRRT use during ICU stay & 2.28 & $2.01-2.59$ & $<0.001$ & 1.97 & $1.64-2.36$ & $<0.001$ \\
\hline Sepsis & $1.91^{\ddagger}$ & $1.76-2.08^{\ddagger}$ & $<0.001^{\text {㧊 }}$ & N/A & N/A & N/A \\
\hline Sepsis* & $1.78^{\ddagger}$ & $1.64-1.94^{\neq}$ & $<0.001^{\ddagger}$ & N/A & N/A & N/A \\
\hline Septic shock & 1.95 & $1.76-2.16$ & $<0.001$ & 1.45 & $1.28-1.65$ & $<0.001$ \\
\hline Septic shock* & $1.78^{\ddagger}$ & $1.60-1.98^{\ddagger}$ & $<0.001^{\ddagger}$ & 1.35 & $1.19-1.54$ & $<0.001$ \\
\hline
\end{tabular}

The odds ratio for bio-ADM was calculated on a base 2 logarithmic scale. Age was included as a covariate in all regressions not including simplified acute physiology score III (SAPS3), as this is already an integral part of SAPS3. An additional covariate for the ${ }^{\dagger}$ model was lactate, and for the * models, the SAPS3 was included. If the Hosmer-Lemeshow test was $p<0.05$, the model was marked ${ }^{\ddagger}$. ICU: intensive care unit; OR: odds ratio; Cl: confidence interval; SOFA: Sequential Organ Failure Assessment; CRRT: continuous renal replacement therapy; N/A: not applicable

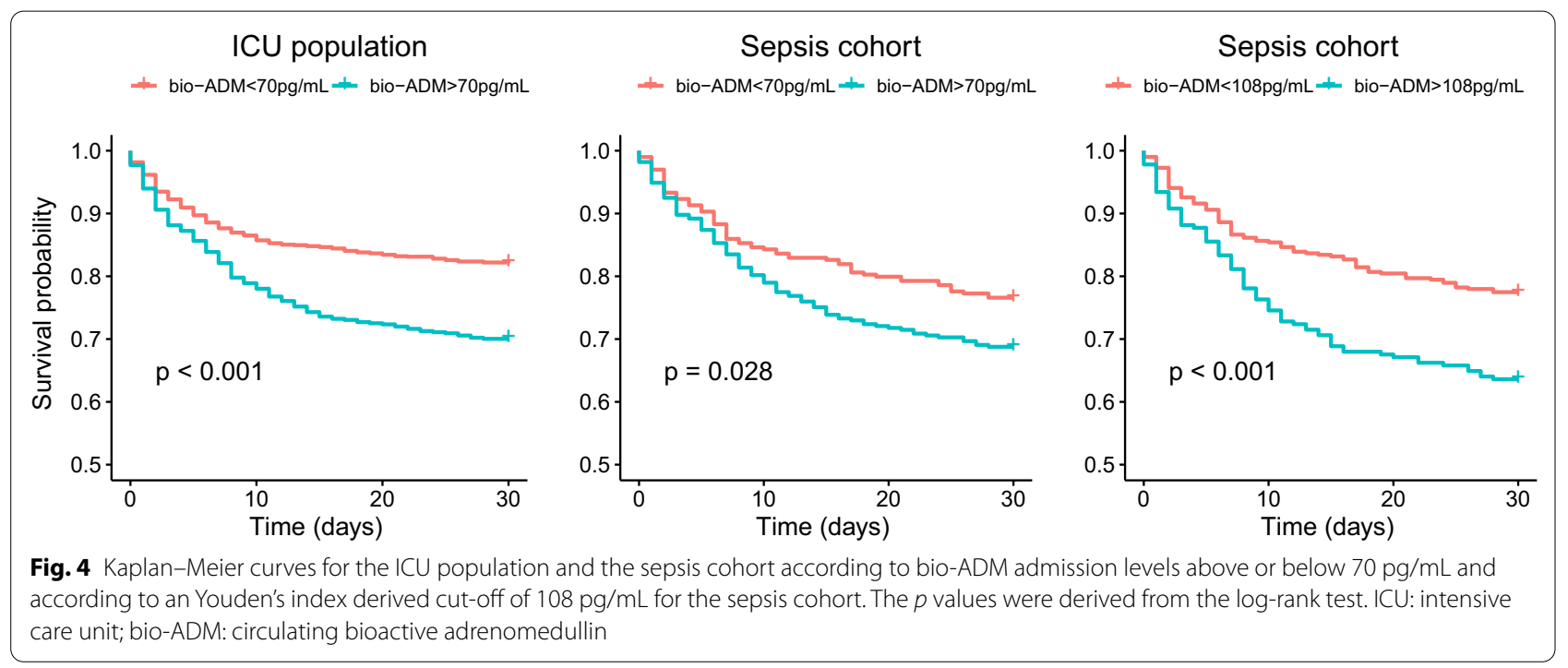

that time. Our time constraint may have underestimated the diagnostic value of bio-ADM in sepsis. On the other hand, our method of retrospectively identifying patients fulfilling the sepsis criteria has probably identified patients who were not considered clinically septic by the treating physician.

We were confined to admission samples only, and could not investigate dynamic changes in bio-ADM levels and the impact these may have had on reported outcomes.

The mortality rate in our sepsis and septic shock subgroups was somewhat lower than expected, which could make our results difficult to generalise to patient populations outside of Scandinavia.

\section{Conclusion}

Elevated admission bio-ADM levels correlate with higher 30-day mortality and an increasing need for organ support in both sepsis and non-sepsis ICU patients. BioADM may be an early morbidity-independent marker of sepsis.

\section{Supplementary information}

Supplementary information accompanies this paper at https://doi. org/10.1186/s13054-020-03351-1.

Additional file 1. Table S1: Suspected focus of infection and culture findings in the sepsis cohort. Table S2: Cutoffs, their corresponding positive and negative predictive values, likelihood ratios and AUCs for the 
different biomarkers. Figure S1: Sepsis patients according to shock status and 30-day survival with one of the eight most common bacteria found in blood cultures are plotted in relation to the suspected focus of infection on ICU admission.

\section{Abbreviations}

ADM: Adrenomedullin; AUC: Area under the curve; bio-ADM: Circulating bioactive adrenomedullin; Cl: Confidence interval; CRP: c-reactive protein;

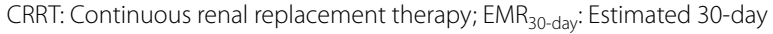
mortality risk; ICU: Intensive care unit; IQR: Interquartile range; MR-proADM: Mid regional pro adrenomedullin; N/A: Not applicable; OR: Odds ratio; ROC: Receiver operating characteristic; SAPS3: Simplified acute physiology score III; PASIVA: Patient administrative system for intensive care units; SOFA: Sequential organ failure assessment.

\section{Acknowledgements}

We would like to thank all staff at the ICUs of Skåne University Hospital in Malmö and Lund, Helsingborg Hospital and Kristianstad Hospital for their contribution to this study. We also extend special thanks to Professor Peter Nilsson of Lund University. This study would not have been possible without the kind contribution of SphingoTec GmbH who analysed our blood samples free of charge.

\section{Authors' contributions}

HF and AF designed the study. OL, ML, MA, MS and HL participated in data collection. OL interpreted the data and performed statistical analyses. $\mathrm{OL}$ and $M L$ wrote the first draft of the manuscript. All authors read, provided critical revision of, and approved the final manuscript.

\section{Funding}

Open Access funding provided by Lund University. Regional research support, Region Skåne; Government funding of clinical research within the Swedish National Health Services (ALF); Biobanking and BioMolecular resources Research Infrastructure (BBMRI, Sweden); Hans-Gabriel and Alice TrolleWachtmeister Foundation for Medical Research; European Union Interreg programme IV A. The funding organisations had no role in the design and conduct of the study; collection, management, analysis, and interpretation of the data; preparation, review, or approval of the manuscript; and decision to submit the manuscript for publication.

\section{Availability of data materials}

The datasets generated and analysed during the current study are not publicly available due to limitations in the ethical approval of the study and data management policies of Region Skåne but are available from the corresponding author on request.

\section{Ethics approval and consent to participate}

The study was approved by the Regional Ethical Committee in Lund, Sweden, with reference numbers DNR 2015/267 and DNR 2017/802. An opt-out procedure made a withdrawal of participation possible.

\section{Consent for Publication}

Not applicable.

\section{Competing interests}

$\mathrm{OL}, \mathrm{ML}, \mathrm{MS}, \mathrm{MA}, \mathrm{HL}, \mathrm{AF}$ and $\mathrm{HF}$ declare that they have no competing interests, no financial or any other interests in SphingoTec $\mathrm{GmbH}$ and have not been in any way influenced by SphingoTec $\mathrm{GmbH}$ in writing this research paper. $\mathrm{OM}$ is listed as an inventor on a patent on bio-ADM in dementia prediction. SphingoTec GmbH is the owner of the patent. DB and JS are employed by SphingoTec $\mathrm{GmbH}$ and participate in the company's employee stock option program. Bioactive ADM was analysed free of charge by SphingoTec GmbH, Neuendorfstrae 15A, 16761 Hennigsdorf, Germany.

\section{Author details}

${ }^{1}$ Department of Clinical Medicine, Anaesthesiology and Intensive Care, Lund University, 22185 Lund, Sweden. ${ }^{2}$ Department of Intensive and Perioperative Care, Skåne University Hospital, 20502 Malmö, Sweden. ${ }^{3}$ Department of Anaesthesia and Intensive Care, Kristianstad Hospital, 29133 Kristianstad,
Sweden. ${ }^{4}$ Department of Anaesthesia and Intensive Care, Helsingborg Hospital, 25437 Helsingborg, Sweden. ${ }^{5}$ SphingoTec GmbH, 16761 Henningsdorf, Germany. ${ }^{6}$ Department of Infectious diseases, Skåne University Hospital, 20502 Malmö, Sweden. ${ }^{7}$ Department of Internal medicine, Skåne University Hospital, 20502 Malmö, Sweden.

Received: 2 June 2020 Accepted: 16 October 2020

Published online: 04 November 2020

\section{References}

1. World Health Organization: Improving the prevention, diagnosis and clinical management of sepsis: report by the secretariat, 6 (2017)

2. Seymour CW, Kennedy JN, Wang S, Chang CH, Elliott CF, Xu Z, Berry S, Clermont G, Cooper G, Gomez H, Huang DT, Kellum JA, Mi Q, Opal SM, Talisa V, van der Poll T, Visweswaran S, Vodovotz Y, Weiss JC, Yealy DM, Yende S, Angus DC. Derivation, validation, and potential treatment implications of novel clinical phenotypes for sepsis. JAMA. 2019;321 (20):200317. https://doi.org/10.1001/jama.2019.5791.

3. Kitamura K, Kangawa K, Kawamoto M, Ichiki Y, Nakamura S, Matsuo H, Eto T. Adrenomedullin: a novel hypotensive peptide isolated from human pheochromocytoma. Biochem Biophys Res Commun. 1993;192(2):55360. https://doi.org/10.1006/bbrc.1993.1451.

4. Hinson JP, Kapas S, Smith DM. Adrenomedullin, a multifunctional regulatory peptide. Endocr Rev. 2000;21(2):138-67. https://doi.org/10.1210/ edrv.21.2.0396.

5. Samson WK, Resch ZT, Murphy TC, Vargas TT, Schell DA. Adrenomedullin: is there physiological relevance in the pathology and pharmacology? News Physiol Sci. 1999;14:255-9.

6. Zudaire E, Portal-Nunez S, Cuttitta F. The central role of adrenomedullin in host defense. J Leukoc Biol. 2006;80(2):237-44. https://doi.org/10.1189/ jlb.0206123.

7. Lainchbury JG, Troughton RW, Lewis LK, Yandle TG, Richards AM, Nicholls MG. Hemodynamic, hormonal, and renal effects of short-term adrenomedullin infusion in healthy volunteers. J Clin Endocrinol Metab. 2000;85(3):1016-20.

8. Nicholls MG, Lainchbury JG, Lewis LK, McGregor DO, Richards AM, Troughton RW, Yandle TG. Bioactivity of adrenomedullin and proadrenomedullin n-terminal 20 peptide in man. Peptides. 2001;22(11):1745-52.

9. Geven C, Bergmann A, Kox M, Pickkers P. Vascular effects of adrenomedullin and the anti-adrenomedullin antibody adrecizumab in sepsis. Shock. 2018;50(2):132-40. https://doi.org/10.1097/SHK.0000000000001103.

10. Christ-Crain M, Morgenthaler NG, Struck J, Harbarth S, Bergmann A, Muller B. Mid-regional pro-adrenomedullin as a prognostic marker in sepsis: an observational study. Crit Care. 2005;9(6):816-24. https://doi. org/10.1186/cc3885.

11. Guignant C, Voirin N, Venet F, Poitevin F, Malcus C, Bohe J, Lepape A, Monneret $G$. Assessment of pro-vasopressin and pro-adrenomedullin as predictors of 28-day mortality in septic shock patients. Intensive Care Med. 2009;35(11):1859-67. https://doi.org/10.1007/s00134-009-1610-5.

12. Marino R, Struck J, Maisel AS, Magrini L, Bergmann A, Di Somma S. Plasma adrenomedullin is associated with short-term mortality and vasopressor requirement in patients admitted with sepsis. Crit Care. 2014;18(1):34. https://doi.org/10.1186/cc13731.

13. Lundberg OH, Bergenzaun L, Ryden J, Rosenqvist M, Melander O, Chew MS. Adrenomedullin and endothelin-1 are associated with myocardial injury and death in septic shock patients. Crit Care. 2016;20(1):178. https ://doi.org/10.1186/s13054-016-1361-y.

14. Caironi P, Latini R, Struck J, Hartmann O, Bergmann A, Maggio G, Cavana M, Tognoni G, Pesenti A, Gattinoni L, Masson S, Investigators AS. Circulating biologically active adrenomedullin (bio-adm) predicts hemodynamic support requirement and mortality during sepsis. Chest. 2017;152(2):31220. https://doi.org/10.1016/j.chest.2017.03.035.

15. Mebazaa A, Geven C, Hollinger A, Wittebole X, Chousterman BG, Blet A, Gayat E, Hartmann O, Scigalla P, Struck J, Bergmann A, Antonelli M, Beishuizen A, Constantin JM, Damoisel C, Deye N, Di Somma S, Dugernier T, Francois B, Gaudry S, Huberlant V, Lascarrou JB, Marx G, Mercier E, Oueslati H, Pickkers P, Sonneville R, Legrand M, Laterre PF, Adren OSSsi. Circulating adrenomedullin estimates survival and reversibility of organ failure in sepsis: the prospective observational multinational adrenomedullin and outcome 
in sepsis and septic shock-1 (adrenoss-1) study. Crit Care 2018;22(1):354. https://doi.org/10.1186/s13054-018-2243-2

16. Kim H, Hur M, Struck J, Bergmann A, Di Somma S. Circulating biologically active adrenomedullin predicts organ failure and mortality in sepsis. Ann Lab Med. 2019;39(5):454-63. https://doi.org/10.3343/alm.2019.39.5.454.

17. Khan SQ, O'Brien RJ, Struck J, Quinn P, Morgenthaler N, Squire I, Davies J, Bergmann A, Ng LL. Prognostic value of midregional pro-adrenomedullin in patients with acute myocardial infarction: the lamp (leicester acute myocardial infarction peptide) study. J Am Coll Cardiol. 2007;49(14):1525-32. https ://doi.org/10.1016/j.jacc.2006.12.038.

18. Maisel A, Mueller C, Nowak RM, Peacock WF, Ponikowski P, Mockel M, Hogan C, Wu AH, Richards M, Clopton P, Filippatos GS, Di Somma S, Anand I, Ng LL, Daniels LB, Neath SX, Christenson R, Potocki M, McCord J, Hartmann O, Morgenthaler NG, Anker SD. Midregion prohormone adrenomedullin and prognosis in patients presenting with acute dyspnea: results from the bach (biomarkers in acute heart failure) trial. J Am Coll Cardiol. 2011;58(10):105767. https://doi.org/10.1016/j.jacc.2011.06.006.

19. Schuetz P, Wolbers M, Christ-Crain M, Thomann R, Falconnier C, Widmer I, Neidert S, Fricker T, Blum C, Schild U, Morgenthaler NG, Schoenenberger R, Henzen C, Bregenzer T, Hoess C, Krause M, Bucher HC, Zimmerli W, Mueller B. Prohormones for prediction of adverse medical outcome in communityacquired pneumonia and lower respiratory tract infections. Crit Care. 2010;14(3):106. https://doi.org/10.1186/cc9055.

20. Stolz D, Christ-Crain M, Morgenthaler NG, Miedinger D, Leuppi J, Muller C, Bingisser R, Struck J, Muller B, Tamm M. Plasma pro-adrenomedullin but not plasma pro-endothelin predicts survival in exacerbations of copd. Chest. 2008:134(2):263-72. https://doi.org/10.1378/chest.08-0047.

21. SelfWH, Storrow AB, Hartmann O, Barrett TW, Fermann GJ, Maisel AS, Struck J, Bergmann A, Collins SP. Plasma bioactive adrenomedullin as a prognostic biomarker in acute heart failure. Am J Emerg Med. 2016;34(2):257-62. https ://doi.org/10.1016/j.ajem.2015.10.033.

22. Yuyun MF, Narayan HK, Quinn PA, Struck J, Bergmann A, Hartmann O, Ng LL. Prognostic value of human mature adrenomedullin in patients with acute myocardial infarction. J Cardiovasc Med (Hagerstown). 2017;18(1):42-50. https://doi.org/10.2459/JCM.0000000000000299.

23. Kremer D, Ter Maaten JM, Voors AA. Bio-adrenomedullin as a potential quick, reliable, and objective marker of congestion in heart failure. Eur J Heart Fail. 2018;20(9):1363-5. https://doi.org/10.1002/ejhf.1245.

24. Ter Maaten JM, Kremer D, Demissei BG, Struck J, Bergmann A, Anker SD, Ng LL, Dickstein K, Metra M, Samani NJ, Romaine SPR, Cleland J, Girerd N, Lang CC, van Veldhuisen DJ, Voors AA. Bio-adrenomedullin as a marker of congestion in patients with new-onset and worsening heart failure. Eur J Heart Fail. 2019;21(6):732-43. https://doi.org/10.1002/ejhf.1437.

25. Morgenthaler NG, Struck J, Alonso C, Bergmann A. Measurement of midregional proadrenomedullin in plasma with an immunoluminometric assay. Clin Chem. 2005:51(10):1823-9. https://doi.org/10.1373/clinchem.2005.051110.

26. Hippenstiel S, Witzenrath M, Schmeck B, Hocke A, Krisp M, Krull M, Seybold J, Seeger W, Rascher W, Schutte H, Suttorp N. Adrenomedullin reduces endothelial hyperpermeability. Circ Res. 2002;91(7):618-25.

27. Ertmer C, Morelli A, Rehberg S, Lange M, Hucklenbruch C, Van Aken $\mathrm{H}_{\text {, }}$ Booke M, Westphal M. Exogenous adrenomedullin prevents and reverses hypodynamic circulation and pulmonary hypertension in ovine endotoxaemia. Br J Anaesth. 2007:99(6):830-6. https://doi.org/10.1093/bja/aem295.

28. Temmesfeld-Wollbruck B, Brell B, David I, Dorenberg M, Adolphs J, Schmeck B, Suttorp N, Hippenstiel S. Adrenomedullin reduces vascular hyperpermeability and improves survival in rat septic shock. Intensive Care Med. 2007;33(4):703-10. https://doi.org/10.1007/s00134-007-0561-y.

29. Kox M, Pickkers P. Adrenomedullin: its double-edged sword during sepsis slices yet again. Intensive Care Med Exp. 2014;2(1):1. https://doi. org/10.1186/2197-425X-2-1.

30. Struck J, Hein F, Karasch S, Bergmann A. Epitope specificity of anti-adrenomedullin antibodies determines efficacy of mortality reduction in a cecal ligation and puncture mouse model. Intensive Care Med Exp. 2013;1 (1):22. https://doi.org/10.1186/2197-425X-1-3.

31. Geven C, Blet A, Kox M, Hartmann O, Scigalla P, Zimmermann J, Marx G, Laterre PF, Mebazaa A, Pickkers P. A double-blind, placebo-controlled, randomised, multicentre, proof-of-concept and dose-finding phase ii clinical trial to investigate the safety, tolerability and efficacy of adrecizumab in patients with septic shock and elevated adrenomedullin concentration (adrenoss-2). BMJ Open. 2019;9(2):024475. https://doi.org/10.1136/bmjop en-2018-024475.
32. Von Elm E, Altman DG, Egger M, Pocock SJ, Gøtzsche PC, Vandenbroucke JP. The strengthening the reporting of observational studies in epidemiology (strobe) statement: guidelines for reporting observational studies. Ann Intern Med. 2007;147(8):573-7.

33. Lengquist M, Lundberg OHM, Spangfors M, Annborn M, Levin H, Friberg $H$, Frigyesi A. Sepsis is underreported in swedish intensive care units: a retrospective observational multicentre study. Acta Anaesthesiol Scand. 2020;64(8):1167-76. https://doi.org/10.1111/aas.13647.

34. Singer M, Deutschman CS, Seymour CW, Shankar-Hari M, Annane D, Bauer M, Bellomo R, Bernard GR, Chiche J-D, Coopersmith CM, Hotchkiss RS, Levy MM, Marshall JC, Martin GS, Opal SM, Rubenfeld GD, van der Poll T, Vincent $\mathrm{J}-\mathrm{L}$, Angus DC. The third international consensus definitions for sepsis and septic shock (Sepsis-3). JAMA. 2016;315(8):801-10.

35. Weber J, Sachse J, Bergmann S, Sparwaßer A, Struck J, Bergmann A. Sandwich immunoassay for bioactive plasma adrenomedullin. J Appl Lab Med. 2019;2(2):222-33. https://doi.org/10.1373/jalm.2017.023655.

36. Nordlund P,Walther S. Riskjusteringsmodeller inom svensk intensivvård. 2019. https://www.icuregswe.org/globalassets/publikationer/fokusrappo rter/fokusrapport_riskjustering_i_sir.pdf. Accessed 01 Oct 2019

37. Moreno RP, Metnitz PG, Almeida E, Jordan B, Bauer P, Campos RA, lapichino G, Edbrooke D, Capuzzo M, Le Gall J-R. SAPS 3-from evaluation of the patient to evaluation of the intensive care unit. Part 2: development of a prognostic model for hospital mortality at ICU admission. Intensive Care Med. 2005;31(10):1345-55.

38. Hosmer DW, Lemeshow S. Assessing the fit of the model, Chap 5. Hoboken: Wiley; 2005. p. 143-202. https://doi.org/10.1002/0471722146.ch5.

39. Harrington DP, Fleming TR. A class of rank test procedures for censored survival data. Biometrika. 1982;69(3):553.

40. Fawcett T. An introduction to ROC analysis. Pattern Recogn Lett. 2006;27(8):861-74. https://doi.org/10.1016/j.patrec.2005.10.010.

41. DeLong ER, DeLong DM, Clarke-Pearson DL. Comparing the areas under two or more correlated receiver operating characteristic curves: a nonparametric approach. Biometrics. 1988;44(3):837.

42. Ranganathan S, Nakai K, Schönbach C. Encyclopedia of bioinformatics and computational biology: $\mathrm{ABC}$ of bioinformatics, vol 1-3. 1st ed. Amsterdam: Elsevier; 2019

43. Wilhelms S, Huss F, Granath G, Sjöberg F. Assessment of incidence of severe sepsis in Sweden using different ways of abstracting international classification of diseases codes: difficulties with methods and interpretation of results. Crit Care Med. 2010;38(6):1442.

44. Fleischmann-Struzek C, Thomas-Ruddel DO, Schettler A, Schwarzkopf D, Stacke A, Seymour CW, Haas C, Dennler U, Reinhart K. Comparing the validity of different ICD coding abstraction strategies for sepsis case identification in German claims data. PLOS ONE. 2018;13(7):0198847.

45. Blet A, de Roquetaillade C, Hartmann O, Struck J, Mebazaa A, Chousterman $B G$, Adrenoss-1 study i. Added value of serial bio-adrenomedullin measurement in addition to lactate for the prognosis of septic patients admitted to ICU. Crit Care. 2020;24(1):69. https://doi.org/10.1 186/s13054-020-2794-x

46. Lemasle L, Blet A, Geven C, Cherifa M, Deniau B, Hollinger A, Fournier MC, Monnet X, Rennuit I, Darmon M, Laterre PF, Struck J, Hartmann O, Bergmann A, Mebazaa A, Gayat E. Bioactive adrenomedullin, organ support therapies, and survival in the critically ill: results from the French and European outcome registry in ICU study. Crit Care Med. 2020:48(1):49-55. https://doi. org/10.1097/CCM.0000000000004044.

47. Rhodes A, Evans LE, Alhazzani W, Levy MM, Antonelli M, Ferrer R, Kumar A, Sevransky JE, Sprung CL, Nunnally ME, Rochwerg B, Rubenfeld GD, Angus DC, Annane D, Beale RJ, Bellinghan GJ, Bernard GR, Chiche JD, Coopersmith C, De Backer DP, French CJ, Fujishima S, Gerlach H, Hidalgo JL, Hollenberg SM, Jones AE, Karnad DR, Kleinpell RM, Koh Y, Lisboa TC, Machado FR, Marini JJ, Marshall JC, Mazuski JE, Mclntyre LA, McLean AS, Mehta S, Moreno RP, Myburgh J, Navalesi P, Nishida O, Osborn TM, Perner A, Plunkett CM, Ranieri M, Schorr CA, Seckel MA, Seymour CW, Shieh L, Shukri KA, Simpson SQ, Singer M, Thompson BT, Townsend SR, Van der Poll T, Vincent JL, Wiersinga WJ, Zimmerman JL, Dellinger RP. Surviving sepsis campaign: international guidelines for management of sepsis and septic shock: 2016. Intensive Care Med. 2017:43(3):304-77.

\section{Publisher's Note}

Springer Nature remains neutral with regard to jurisdictional claims in published maps and institutional affiliations. 